\title{
Estrategias publicitarias en escenarios culturales
}

Recibido: 01 de septiembre de 2016

Aceptado: 06 de abril de 2017

Publicado: 27 de noviembre de 2017
Enrique Mena García

emena2@ucam.edu

Universidad Católica de Murcia (España)

Resumen: Nuestra herramienta es el marketing sujetado al incipiente mercado cultural que está en auge y que no cesa de crecer y que acoge cada vez a más sectores diversos de población gracias a toda la disparidad de ofertas. Ese mercado o marketing cultural lo analizamos desde una esfera publicitaria, dentro de una de las “4P's" del marketing mix, la promoción, afianzado con ejemplos en museos. Se trata de colocar la obra o pieza artística como eje de todo este entramado, por donde transita también el voraz mercado de compraventa del arte, un terreno cultural próximo y distante a la vez por los desmesurados precios y su desconocimiento. Este lenguaje del arte en museos se acerca a la sociedad gracias a la publicidad e intenta mitigar ese dualismo sociedad-museos, aprovechando el arte para atraer un público más profano o, por contra, fortalecer a aquel que demanda cultura.

Palabras clave: Marketing, museo, cultura, publicidad, arte, promoción.

\begin{abstract}
Our tool is marketing subject to the incipient cultural market that is booming and that does not cease to grow and that increasingly welcomes diverse sectors of the population thanks to all the disparity of offers. This market or cultural marketing we analyze from an advertising sphere, within one of the " 4 P's" of Marketing Mix, promotion, secured with examples in museums. It is a question of placing the work or artistic piece as the axis of all this network, through which the voracious market of buying and selling of the art, cultural terrain close and distant at the same time by their ignorance and unreasonable prices. This language of art in museums is approaching the society thanks to the publicity and tries to mitigate this dualism society-museums, taking advantage of the art to attract an audience more profane or on the contrary, strengthen those who demand culture.
\end{abstract}

Key words: Marketing, Museum, Culture, Advertising, Art, Promotion. 


\section{Introducción}

Suele ser una sorpresa para los que comienzan a estudiar marketing que la parte más importante no consiste en la venta de productos (esa venta es solo la parte visible del iceberg), porque se debe conocer bien el público objetivo y ajustarse a sus necesidades, por tanto, es básico el conocimiento del llamado consumidor, cliente o espectador, poniendo a su disposición el producto o servicio.

Cierto es que el marketing suele crear necesidades y todo lo que se pueda ofrecer debe ir unido a un valor añadido que se debe destacar. En nuestro caso, Colbert y Cuadrado (2015: 24) explican que "el marketing de la cultura y las artes persigue principalmente distribuir o difundir una obra y generar el máximo beneficio posible”. Si hablamos de artes plásticas, el producto es la obra de arte, cuyo objetivo es que el consumidor se aproxime, aprecie y valore la misma.

Lo que pretendemos es (desde un estudio del marketing cultural con el fundamento de la promoción y su ámbito publicitario) clarificar el arte, su contexto y como se mueve en esa permeabilidad de corrientes que hace bascular el negocio del mercado del arte hacia cotas complejas (cuyo sistema cultural de negocio es difícil de medir), y como intentan alcanzar de formas diferentes a un público que necesitan y que genera en las industrias culturales el $3 \%$ del PIB mundial (EY, 2015).

\section{Objetivos}

A través de un apartado del marketing mix (como es la promoción) analizaremos el punto de vista de la publicidad y la creatividad orientada a lo que vende, una creatividad según Navarro (2010: 32) "como punta de lanza de la publicidad". Además, no podemos dejar de mencionar la gratuita publicity, que no se considera publicidad, pero sí una acción consecuente de las relaciones públicas centrada especialmente en los medios y que conlleva la gratuidad de su difusión y de la que se nutre mucho la cultura desde los medios de comunicación.

El arte es el eje de todo este análisis: debe ofrecer una conexión y diálogo con el público. En esta visión de marketing, Hirschman señala tres segmentos de mercado: el primero es el artista o el creador; el segundo segmento lo componen compañeros o colegas de profesión, críticos o profesionales que deben reconocer y valorar la obra, y, por último, el amplio público, dividido en muchos otros, por tanto esa creatividad que posiblemente pudo ser de satisfacción personal de necesidad del creador, salta a considerarse comercial u orientada al mercado (ápud Colbert y Cuadrado, 2015: 25).

Así, descubrimos que los signos del marketing cultural y su promoción van desde un ambient-marketing, teniendo en cuenta al consumidor, quien a veces es todo un experto y cuyo anuncio debe ir en consonancia con la estética del mismo, insertado en lugares propicios, por lo que nuestra hipótesis se dirige al cambio de lo que llamamos posicionamiento del mercado cultural. 
El consumidor de espacios culturales tiene un nivel educativo y cultural al que no vale cualquier campaña, convirtiéndose en un virtual dueño de las marcas. Se trata de transformar espacios, no solo informar como organismo comunicador. De ahí que veamos unos medios exteriores originales, alejados de las vallas, carteles o marquesinas más tradicionales con los que también conviven. Cada año aparecen nuevos formatos de publicidad exterior, al igual que sus ubicaciones, rincones inusuales, tamaños o formas de presentarlos en soportes dispares.

Navarro (2010: 237) sostiene que "el mensaje exterior envejece antes y, cuando esto ocurre, su público deja de mirarlo". Por ese motivo, sugiere que "la renovación periódica del mensaje es conveniente en este medio". Nuestro objetivo busca demostrar que la amplia promoción cultural del arte se establece en los productos o marcas, que transmiten valor, sofisticación y belleza, una constante en centros u organismos culturales.

Se debe cuidar y mimar la "marca" del museo o galería, a fin de potenciarla cada día, porque el mundo es un "bazar cultural" (Olamendi, 2000: 13). Ante la promoción cultural centrada en museos, apuntamos que:

"la publicidad convencional está bajo sospecha continua, recibiendo multitud de críticas que poco a poco van autoimponiendo un ejercicio de obligada corrección política [...] A esa cruda realidad, se le suman otras dos variables no menos importantes. Primera: el mundo de la cultura, en general, no tiene una opinión muy positiva de la publicidad. Algo paradójico, pues se trata de una manifestación más de nuestra esfera cultural contemporánea [...] Segunda: la situación de sobresaturación de la iconósfera comunicativa, que conlleva que los potenciales receptores de los mensajes publicitarios sean cada vez menos receptivos a ellos. Y si hablamos de plataformas o dispositivos móviles digitales como soporte publicitario, este tipo de publicidad causa cada vez más rechazo entre los usuarios, al entenderla como una detestable intromisión en su rápida y compulsiva navegación por la red" (Mateos, 2013: 25).

\section{Evolución del marketing cultural}

En 1967 surgió por primera vez la cuestión del marketing en entidades culturales con los primeros libros sobre el tema. Se reconoce a la Universidad de Yale como la primera en crear un programa de especialización en gestión cultural (1966), a la que le siguieron otras universidades como la City University de Inglaterra, la Academia de Teatro de San Petersburgo y la Universidad de York en Canadá (Colbert y Cuadrado, 2015: 27). Lo anterior evidencia que el interés por el análisis del impacto económico de la cultura nació en los Estados Unidos (Ageteca, 2009).

Como señala Mendoza (2013), el término se refiere "a la estrategia de dar difusión a los proyectos propuestos por las organizaciones o instituciones de carácter propiamente cultural. El modelo de mercadotecnia para la cultura, busca cubrir las necesidades de los consumidores específicamente de este mercado". Y, sobre todo 
“en tareas como investigar sobre cuáles son los canales comunicativos más óptimos para las instituciones públicas o privadas dedicadas al mercado cultural, junto con la utilización de diversas técnicas de investigación (cualitativas o cuantitativas) que ayudan a conocer el perfil del público potencial de una organización" (Mendoza, 2013).

El mencionado autor define el marketing cultural como "el conjunto de acciones y estrategias cuyo objetivo es el de incrementar el interés cultural en la sociedad por medio de la difusión y publicidad, colaborando en el proceso ya sea de formación o consolidación en la imagen de la organización" (Mendoza, 2013).

En los procesos del marketing (dentro de un contexto cultural) entran en juego las organizaciones, sus gestores, los propios artistas o diseñadores, sus obras o creaciones, los curadores (si los hubiera), las agencias de publicidad, las consultorías, entre otros. En definitiva, una esfera muy marketiniana. A ello, le sumamos el nuevo fenómeno de "coaching cultural", cuya labor de perspectiva cultural hace que el coachee (quien es el entrenado o la persona que lo recibe) disminuya su choque cultural y saque el máximo rendimiento de esas metas que el mismo estableció.

La industria cultural ha permitido atraer inversiones, repercutiendo al crecimiento económico, convertida en una generadora de empleo,

"y ya en un nivel más micro, será necesario tomar las decisiones sobre estrategias de 'marketing' requeridas para el logro de los objetivos de la organización cultural o artística. Decisiones tales como el posicionamiento adecuado, segmentación del mercado, diseño del producto y definición de las respectivas estrategias de precio, distribución y promoción. Así, finalmente llegamos a estructurar un plan de marketing” (Gómez Ramírez, 2007: 126).

El turismo cultural se constituye en una vía importante de desarrollo para las entidades escénicas u otros eventos del sector de las artes, acompañado en muchos aspectos, del merchandising que también repercute de una manera importante a la economía del sector. La observación del panorama del mercado de las artes se caracteriza por:

"Ser altamente concentrada: pocos operadores financieramente muy potentes con alta competencia entre ellos. El mercado americano representa la mitad del mercado mundial y la Gran Bretaña un cuarto. Las plazas dominantes en el mundo son en su orden New York, Londres y París. Las dos grandes firmas anglosajonas Sotheby's y Christie's representan casi tres cuartas partes del mercado mundial de ventas públicas. Mientras que Christie's está presente en treinta y siete países con quince salas de venta y numerosas oficinas y organiza más de novecientas ventas de subasta cada año, Sotheby's, que se volvió americana, tiene acciones en la Bolsa de Nueva York y en la de Londres y dispone de centros de venta en catorce países y de oficinas instaladas en todos los continentes" (Gómez Ramírez, 2007: 129). 


\section{El valor cultural}

El producto es altamente influenciado, según su entorno, por el medio o el hábito propio del consumidor. Este entorno tiene una dimensión tecnológica condicionada. En la mitad del siglo XX se fortalece el movimiento del "arte pop" y un impulsor como Warhol, así como la llegada de la televisión y su masificación a lo largo del mundo; la ruptura política del telón de acero con el colapso de la Unión Soviética, la aparición de la Internet, entre otros.

Lo que se debe tener claro es el valor cultural por encima de todo (independientemente del coste de un evento) y las políticas de gobierno en materia cultural tienen que ir dirigidas para compensar y equilibrar a veces ese alto coste cultural, cuya repercusión sociocultural está presente cada vez más en la vida activa de la ciudadanía. La apuesta e inversión por la cultura deben primar, haciendo que el mundo progrese en aspectos de comprensión, sensibilidad, estética, interculturalidad o humanidad.

De acuerdo con Throsby, uno de los aspectos a resaltar en los productos culturales es precisamente su valor cultural, que va más allá del valor estrictamente económico y que suma las siguientes cualidades:

- "Valor estético: hace referencia a los valores relacionados con la belleza y la armonía.

- Valor espiritual: que desarrolla el sentido de pertenencia a un colectivo, a una comunidad (religiosa, de valores, etc.), permitiendo satisfacer necesidades de reconocimiento social, y que nos permiten en gran medida explicar el proceso de decisión de compra del consumidor cultural.

- Valor social: que permite vincular a colectivos que comparten un entorno social (un territorio, un barrio, etc.) a través de la vinculación con valores que comparten y a la vez los diferencian.

- Valor histórico: que permite la conexión con el pasado y mejora la comprensión del contexto actual.

- Valor simbólico: que hace referencia a la imagen que transmite el consumo de productos culturales.

- Valor de autenticidad: que hace referencia al carácter creativo y genuino del propio bien, que hace del producto cultural una experiencia única y personal en la que participan tanto el creador como el cliente que interpreta y hace suya la experiencia de consumo desde su perspectiva" (ápud Leal y Quero, 2011).

Unzueta (2002: 35) establece la relación entre el mercado y el arte, así como su significado en la sociedad contemporánea. Cierto es que el arte y su mercado se ven determinados por una necesidad cultural que surge tanto por parte del artista mismo como por parte de la sociedad que percibe este arte. Esta necesidad cultural puede explicar por partes la existencia de grandes cantidades de fenómenos y movimientos culturales en diferentes décadas. En definitiva, en cualquier actividad económica sin inversión, no sería posible la promoción ni su existencia. 
La actitud del público es esencial, concienciada y comprometida, ya que implica un punto a favor que atrae a más gente. La distinción del público se segmenta o divide en el mercado según comportamientos del consumidor, donde encontramos la dicotomía del comprador / no comprador, junto con indicadores como la frecuencia o tasa de consumo, el grado de lealtad al producto o marca, el nivel de satisfacción del consumidor y la preferencia de marca o producto.

En la sociedad actual de la globalización e información, es indudable que el arte tiene su campo propio, donde recoge un amplio espectro de públicos. Una cosa es la difusión y universalización del arte, que se constata en el creciente número de exposiciones y actos culturales que se ofertan en la actualidad para poder llegar a mucha gente y que puedan acceder a la contemplación de dicho universo, manifestado en el éxito de exposiciones de grandes artistas, como lo demostró Damien Hirst en la Tate Modern de Londres, donde la afluencia de público fue masiva y se podían ver largas colas para acceder $(E F E, 2012)$.

Sin embargo, esta amplia difusión del arte no parece acceder al llamado "mercado del arte", todo un submundo de oferta y demanda desconocido por la gran mayoría. Como indica Unzueta (2002: 35), el consumo o demanda de las obras de arte se basa en dos pilares fundamentales, la necesidad cultural insatisfecha y la dimensión económica de las obras de arte, y ambos pilares delimitan el número de personas con acceso a este mercado.

Durante las crisis económicas, surgen los problemas porque es difícil en muchos hogares cubrir necesidades básicas y las "culturales" pasan a un segundo o tercer plano y se posponen. Por la misma razón, el acceso económico al mercado del arte también está muy limitado. Hay que tener un gran poder adquisitivo y conocimientos financieros para invertir en ese campo, sobre todo teniendo en cuenta las variables concretas de este mercado, donde la rentabilidad no está asegurada y las operaciones hay que plantearlas a largo plazo, condiciones que tan solo cumplen unas pocas personas, lo que resalta la importancia de la vertiente económica del mercado del arte. Un mercado en el que muchas veces prima más el interés rentable o financiero que el propiamente cultural, y quien compra arte lo hace como refugio ante la incertidumbre y volatilidad del mercado actual para conseguir luego una rentabilidad.

\section{Estrategia cultural}

De acuerdo con las premisas de Ageteca (2009), conlleva el desarrollo de un marketing cultural centrado en la "estrategia de difusión de los proyectos y las comunicaciones de acciones culturales que realizan las organizaciones (públicas o privadas) con el fin de generar una imagen positiva en sus públicos". Hablamos de una industria cultural que incluye cine, música, artesanía, bibliotecas, museos, monumentos, artes escénicas, entre otros. Obviamente ante ella debemos preguntarnos: ¿quién es nuestro público $=$ audiencia $=$ espectador?

Solemos apreciar que la participación en actividades culturales disminuye en la etapa juvenil, si nos atenemos a festivales de música, pero aumentan conforme se alcanza un 
mejor nivel educativo, ingresos y estabilidad social, cuando los gustos musicales suelen ser la ópera y la música clásica, cuyos consumidores o clientes sobrepasan los 30 años. "Respecto al género sexo, se conserva la tendencia de un mayor público femenino en exposiciones, museos y sitios históricos, así como visitas a bibliotecas o asistencia a conciertos de música clásica u ópera. En cuanto a teatro, conciertos de rock, de jazz, de pop y al cine, la diferencia en asistencia por géneros es muy escasa" (Gómez Ramírez, 2007: 31).

La UNESCO (2015) reconoce "la falta de estadísticas disponibles en materia de género en el ámbito de la cultura". En ese sentido, la recolección es pobre en el desglose por sexos respecto a la cultura. La cantidad de películas dirigidas por mujeres en festivales nacionales de cine en todos los BRICS (Brasil, Federación Rusa, India, República Popular de China y Sudáfrica) representa algo más del $20 \%$ del total de películas. En otros países, en cambio, como en los Estados Unidos, “el empleo cultural en 2012 representó el 5,7\% de la fuerza laboral activa, y las mujeres representaron el $44,6 \%$ de la totalidad de las ocupaciones culturales" (UNESCO, 2015).

El marketing cultural no suele establecerse en instituciones pequeñas y públicas, que relegan de publicitarse, aunque, por contra, suelen mostrar interesantes Web muy intuitivas y didácticas, muy cuidadas también en las salas privadas o Galerías de Arte, ya que, aunque no cuentan con un gran equipo, la gestión cultural debe ser muy versátil, desde la atención con los medios, el mimo con los críticos, y, que decir con los clientes y el deseo de satisfacerles. También existen detractores ante esto, como algunos curadores de museos, que reprochan al marketing porque trata "de ajustar su misión como un sitio de diversión y de introducir actividades percibidas como fundamentos comerciales que contribuyen a la dilución del contenido cultural” (Gómez Ramírez, 2007: 124).

Relacionado con la labor de las agencias y medios locales, Morte (2004: 117) indica que "el anunciante está dispuesto a invertir dinero en medios, pero no quiere pagar por estrategia y por creatividad" y "otro problema añadido en la falta de cultura de comunicación entre anunciantes locales". El conjunto de herramientas habitual que utiliza una institución o empresa (si tiene los conocimientos o departamento adecuado para alcanzar sus objetivos de marketing en el mercado elegido) es el marketing mix.

Dentro del producto y la marca, en la actualidad es muy común que se reconozcan con facilidad las siglas o símbolos diseñados para ciertas organizaciones culturales, como el MOMA (Museo de Arte Moderno de Nueva York), la marca Guggenheim, el TATE, el Louvre, el prestigio de un ballet ruso, etc. La apuesta de $\mathrm{I}+\mathrm{D}$ de grandes empresas culturales debe funcionar, ser latente, viva y dinámica, así como la continua apuesta de nuevos productos, cuyos lanzamientos son adaptados a los cambios socioculturales.

Esto recuerda al artista francés JR cuando hizo “desaparecer" la pirámide del Louvre en 2016, creando una ilusión óptica del espectador como estrategia de branding asociado a la marca del museo, ya que fue el propio museo quien estaba detrás de esta financiación y que supuso miles de Tweets. El grafitero británico Banksy, cuyo "Street Art" repercute 
interesantes ganancias a las galerías al ofrecer su obra (Vicente, 2016). Estamos viviendo en una época en la que el arte es valorado por la repercusión de una firma y con ello aludimos a un experimento que hizo Banksy, quien vendió algunas de sus obras por sólo 60 dólares en un pequeño puesto en el Central Park, pese a que estas suelen subastarse por 300 mil euros (La Vanguardia, 2013).

Si hablamos de precio, en nuestro caso va unido al caché de una obra o de un evento (a veces gratuito), estando detrás una financiación pública o parte (como colaboración), pero el entramado cultural arrastra seguros o presupuestos destinados a políticas culturales de un gobierno, etc. Los grandes museos están obteniendo considerables ganancias con sus muestras temporales (antológicas o retrospectivas) y su proyección en merchandising. Asimismo, las instituciones culturales deben a día de hoy tener en cuenta las Relaciones Públicas:
"Más allá de la discusión sobre si los editores de blogs o propietarios de perfiles en redes sociales virtuales son prescriptores culturales, pero está claro que cada vez son más las personas que los siguen y hacen caso de sus opiniones y consejos. En algunos casos con un poder de difusión y penetración de esas opiniones que supera en mucho a la de los prescriptores culturales hasta ahora al uso, como periodistas culturales o críticos" (Mateos, 2011).

En la promoción tenemos que dar importancia a los patrocinadores. Es casi inevitable conseguir ayudas cuando una entidad cultural afronta gastos como por ejemplo traer una sinfónica a su ciudad por todo el coste que acarrea y no poder afrontarlo sola. Es un mecenazgo estratégico en toda regla para mejorar su imagen, incrementar sus ventas o para aliviar su situación fiscal. En la literatura y el cine, los museos aparecen como "product placement".

Además, se debe tener en cuenta la estrategia de posicionamiento, a sabiendas lo qué valora el consumidor (el público objetivo o target) del que se debe obtener su fidelidad y agrandar la misma en el mercado. Por ejemplo, en referencia a museos, citamos el fenómeno extendido de participación de familias en talleres donde involucran a los niños en franjas de edades, cumpliendo la estructura didáctica y pedagógica acorde a tal fin. Con esto, podemos poner el ejemplo del museo Thyssen-Bornemisza conocido en pedagogía educativa del arte por su portal Educa Thyssen (educathyssen.org), dirigido a profesores, investigadores, centros educativos, entre otros.

Al diseñarse las campañas publicitarias, los museos emplearon un plan de comunicación preestablecido,

"la primera opción que propusieron los museos para sortear esta compleja realidad de saturación y de falta de credibilidad fue la aplicación de todo un conjunto de acciones de comunicación no convencional [...] Gracias a ese tipo de estrategia comunicativa, los museos fueron capaces de llegar a su público objetivo de forma diferente, ya fuera por dirigirse directamente a él (marketing 
directo o marketing promocional), por el efecto sorpresa (marketing de guerrilla) o por la confianza desprendida (marketing viral o buzz marketing). Cuando todo eso es insuficiente o comienza a serlo, la nueva era de la postpublicidad genera nuevas técnicas como el Content Marketing, que permite a los museos alcanzar sus objetivos comunicacionales" (Mateos, 2013).

\section{Resultados. EI museo a través de su publicidad}

El sistema de museos tradicional se basa en "exposiciones, textos de sala, escenografías, maquetas, catálogos y guías de visita, audioguías, audiovisuales, etc." que avanza a otros más recientes, como "las recreaciones virtuales, guías multimedia, aplicaciones móviles, etc.” (Mateos, 2013) con una presencia cada vez más evidente

“de los métodos y las estrategias del marketing en la gestión del museo moderno. Una integración de las lógicas del marketing que ha comportado muchos cambios en esta venerable institución cultural” (Mateos, 2013).

Las campañas que mejor se promocionan se suelen situar en inauguraciones. Las exposiciones itinerantes o temporales son el reclamo más potente de museos como el Thyssen, el Prado y el Reina Sofía, tal como sucedió en este último con "Piedad y terror en Picasso, El camino a Guernica", con el influyente comisariado de Timothy James Clark y Anne M. Wagner, que "aspira a batir los 730339 visitantes que obtuvo la retrospectiva dedicada a Salvador Dalí en 2013” (Martín, 2017).

Otro ejemplo fue la exposición "El Bosco. La exposición del V Centenario" (2016), la cual tuvo que ampliarse un mes en el museo del Prado por la demanda de público, el cual tuvo sus salas congestionadas y saturadas. El Bosco alcanzó los 589692 visitantes, superando al año anterior en un $12.50 \%$, con unos ingresos que superaron los veinte millones de euros (Cadena Ser, 2017).

Figuras 1 y 2: Paneles del Museo del Prado (2016), así como su ampliación (2007).
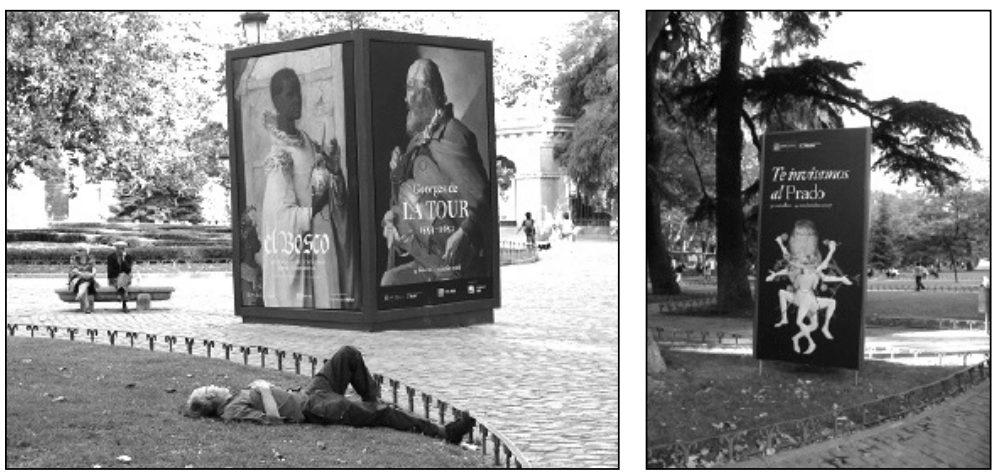

Fuentes: Mateos (2016) y Jiménez (2007). 
La campaña de la agencia DCS Porto Alegre (figura 3) mostró obras modificadas de Lichtenstein Botero y Munch, en las cuales primaba el retrato enmarcado de personas reales, señalando que el público era el factor vital de todo museo (Mena, 2016: 108). Esto recuerda toda la apropiación que se le hace al arte, de cómo la publicidad se ayuda o se apropia del arte para crear y (se quiera o no) el hecho de versionar o manipular una obra de arte, como tantas veces se ha hecho con la Gioconda de Leonardo da Vinci.

Figuras 3 y 4: Publicidad del Museo Margs (Porto Alegre, Brasil) y campaña navideña de museos romanos.
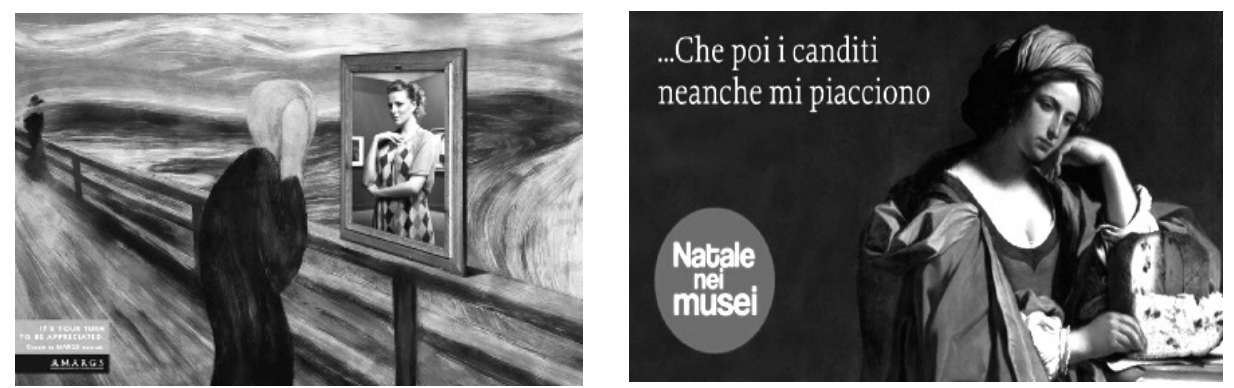

Fuentes: Ads of the World (2009) y La Repubblica (2017).

Subrayamos el caso del Museo de Londres, cuya estrategia de rebranding buscó un decidido reposicionamiento en la mente de las personas, con una renovación y giro estético muy visible al exterior:

"Para conseguir ese re-engaging con los londinenses, el museo lanza en 2010 la campaña publicitaria convencional 'You are here', ideada por el estudio de branding y comunicación NB Studio, compuesta de vallas en el tuve londinense, instalaciones publicitarias en lugares significativos de la ciudad, piezas gráficas en periódicos y revistas, etc. Su concepto creativo se basó en la superposición de imágenes históricas en espacios urbanos actuales" (Mateos, 2013: 21).

Otro caso es el encargo del Museo Van Gogh de Ámsterdam para realizar un cómic extenso a modo de novela gráfica "Vincent van Gogh: An Artist's Struggle" (2011), escrita por Jan Kragt y Marc Verhaegen, quien también ilustra (Mateos, 2013: 20). Habitual es que las artes apoyadas en la publicidad en la París de fines del XIX tuvieran como soporte el cartel o póster, una herramienta de apoyo en cabarets, óperas, teatros y restaurantes realizados por artistas como Toulouse-Lautrec o Jules Cheret. Ese trabajo pervive en el cartelismo desarrollado por el Museo de Orsay (2011) con motivo de una exposición de impresionistas con el eslogan Un nouveau regard ("Una nueva mirada") y Nous avons revu Orsay. Tout est à revoir ("Hemos revisado Orsay. Todo está por redescubrir"). 
Figuras 5 y 6: Cartel publicitario del Museo de Orsay y

Campaña de la Fundación Amigos del Museo del Prado.
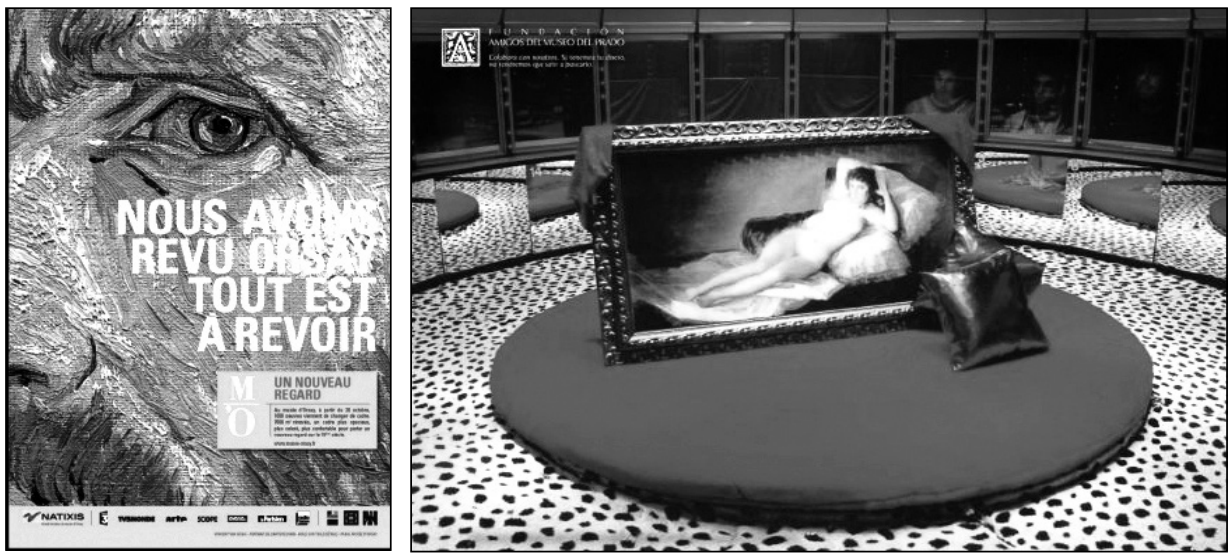

Fuentes: Museo de Orsay (2006) y Coloribus (2002).

Al igual que la Fundación Amigos del Museo del Prado, que promocionaba a la Maja Desnuda de Goya en un gran diván circular (figura 6), a modo de salita de los espejos de las antiguas salas "peep show", con alfombra de terciopelo blanco de manchas negras.

\section{Conclusiones}

Creemos que toda la apropiación que realiza la publicidad sobre la historia del arte, beneficia a ese mismo arte, aunque sea desfigurado, pero que desprende cierto magnetismo en el público ya sea conocedor (o no) del arte. Ese bagaje cultural aumenta por el solo hecho de salir a la calle en modo publicidad. Con esa forma distorsionada de ofrecer el arte, posiblemente parte del público se interese en descubrir las obras reales en el propio museo al que pertenecen, gracias a que estas (ya no tan desconocidas) actúan de reclamo publicitario y, por supuesto, suelen ser cabezas visibles de la colección de dicha institución.

Actualmente, existe una difusión cada vez mayor del arte para todo tipo de público. Un arte puesto al servicio de la sociedad. Este es el que recogemos en los ejemplos vistos con la promoción en museos, cuya imagen transmitida genera un impacto positivo, ya que son indicativos del alto índice cultural de una ciudad, el cual entusiasma al turista y reconforta a aquella sociedad de pertenencia, demostrando con su nivel promocional el grado de ciudad que es y el patrimonio que esconde, del cual uno forma parte.

En el análisis ilustrado tenemos la promoción clásica, que procede del cartelismo parisino (como pueden ser banderolas y displays) sólo alterado en dimensiones. Lo interesante de estos ejemplos es como los museos han sabido adaptarse a las nuevas tecnologías (aplicaciones y realidad aumentada, medianeras de edificios, formatos cúbicos). En esta situación hay que destacar cómo con esa realimentación del arte que hace la publicidad 
es capaz de buscar un giro drástico y hacer pensar al espectador, descontextualizando a la obra de la maja desnuda en un diván erótico y el personaje del popular cuadro "El grito" con sus habituales manos en la cabeza, perplejo al observar la inversión entre lo expuesto y el espectador, sintiéndose observado por un cuadro que a su vez hace de ventana a la espectadora que lo contempla.

En este análisis existe un tercer elemento en todo ello: el museo sale a la calle, se democratiza, se integra con la sociedad, como la "Noche de los Museos", donde el espectáculo absorbe al viandante y las obras de arte reclaman su momento, su atención, porque están más vivas, son de todos y te solicitan.

En todo caso, continúa existiendo un mercado del arte reducido y elitista en el que prima más la dimensión económico-financiera que la cultural. Aunque el mercado del arte no siempre es elitista, a veces esos agentes son instituciones que apuestan por el intercambio de obras o fondos de su patronato para adquirir una obra que sigue las líneas estéticas con las que se identifica, etc. Son apuestas para la sociedad, a fin de albergarlas en sus colecciones públicas por diversos motivos, desde provocar un tirón mayor de público, por su aspecto histórico o para completar y dar coherencia a la línea seguida de una sala o autor.

También nos consta que las galerías de arte apuestan por artistas emergentes y ofrecen precios semi-populares en colectivas y con posibilidades de financiación, con obra gráfica seriada o de formato pequeño que atrae a un comprador joven (pero estable laboralmente), emprendedor, sensible y generalmente sin afán coleccionista, que pretende tener una obra que llene un adecuado espacio y aporte una especial sensación interior.

La escena descrita de Banksy vendiendo sus obras, refleja que el arte no solo va relacionado con la obra artística, sino también con los activos del mercado, variables como el adelantarse a las corrientes a modo de visionarios, la exclusividad, la marca la cual se convierte en la firma y el riesgo, todas difíciles de enfocar cuantitativamente. Incluso influye un "espaldarazo" de un asesor, agente o manager, como así sucede con representantes de actores, cantantes y demás gente del espectáculo, cuyas intervenciones en escena dependen en parte de este fenómeno perteneciente a la misma industria. Quizá esta sea la perversión del mercado en las sociedades complejas del siglo en el que nos encontramos.

Las modas y la importancia cultural no nacen ni se desarrollan solitariamente o "por arte de magia" están atadas a discursos económicos y políticos hegemónicos; lo que puede derivar en la denigración, subvaloración o atropello de otras culturas, pues no es válido hablar de "la cultura" sino, mucho mejor de "las culturas", como gran valor.

Sorprendente es que el teatro musical en España haya tenido tan buena acogida en ciudades de peso que arrastran una gran infraestructura. Hablamos de espectáculos de calidad que llegan a una gran ciudad que a su vez recibe miles de turistas al mes, como sucede con los musicales de Broadway, que pueden estar repitiéndose hasta la eternidad. Debemos entender que una producción de estas características necesita un mayor presupuesto y esto hace que el precio de las entradas sea mucho más cara, como 
puede ser la puesta en escena en decorados y personajes de una ópera como Turandot. Aunque el fin es que nunca se baje el telón, prosiga la cultura, alimente a la familia del espectáculo, generando beneficios aún a pesar de la crisis.

Nuestra conclusión es que se puede tener un gran producto, pero se debe potenciar a través de los canales de marketing disponibles para conseguir una estabilidad en cuanto a ingresos y tiempo en cartel. El mercado mundial del ocio y la cultura en las últimas décadas ha ido creciendo y obteniendo popularidad entre un público más amplio, como así lo demuestran espectáculos como El Circo del Sol, exposiciones antológicas o retrospectivas como la nombrada de El Bosco en el Prado, entre otros.

Según Palma y Aguado (2011: 222) existen dos tareas a desarrollar en toda política cultural:

- "El refinamiento de los métodos estadísticos y el desarrollo y/o aplicación de nuevas metodologías para la valoración de bienes culturales y poder, aunque parcialmente, cuantificar las externalidades que el arte y la cultura producen.

- Generar consumidores con experiencia', dado que sólo el consumidor con experiencia sería el justo juez de lo que se considera arte y cultura y, podría, con sus preferencias y votos monetarios, decidir el conjunto de bienes culturales disponibles en el mercado y cuáles se conservan para las generaciones futuras".

\section{Fuentes consultadas}

Ads of the World (2009). "MARGS Munch". Extraída el 16/X/2017 desde https:// adsoftheworld.com/media/print/margs_munch

Ageteca (2009). "Economía de la cultura". Extraída el 11/X/2017 desde http://www. agetec.org/ageteca/economia.htm

Cadena Ser (2017, enero 2). "El Prado recibió más de 3 millones de visitantes en 2016, un 12.50\% más". Extraída el 16/X/2017 desde http://cadenaser.com/ser/2017/01/02/cultura/1483383874_521016.html

Colbert, F. y Cuadrado, M. (2015). Marketing de las artes y la cultura. Barcelona: Ariel.

Coloribus (2002). "Peep Show”. Extraída el 16/X/2017 desde https:/www.coloribus.com/ es/adsarchive/prints/fundacion-amigos-del-museo-del-prado-peep-show-14650055/

$\boldsymbol{E F E}$ (2012, septiembre 17). "La muestra de Damien Hirst, la más visitada de la historia de la Tate Modern”. Extraída el 12/X/2017 desde http://www.abc.es/20120917/cultura-arte/ abci-damien-hirst-tate-modern-201209171803.html 
EY (2015). "Tiempos de cultura. El primer mapa mundial de las industrias culturales y creativas". Extraída el 11/X/2017 desde http://www.worldcreative.org/wp-content/ uploads/2016/03/EYCulturalTimes2015_ES_Download.pdf

Gómez Ramírez, C. (2007). "Marketing cultural”. Revista EAN, núm. 60, pp. 123-146. Extraída el 11/X/2017 desde http://www.redalyc.org/html/206/20606007/

Jiménez Rodríguez, R. (2007, noviembre 2). "Primera aproximación al 'nuevo' Museo del Prado". Extraída el 16/X/2017 desde https://canarioenmadrid.com/2007/11/02/primeraaproximacion-al-nuevo-museo-del-prado/

La Repubblica (2017, enero 2). "Roma, la campagna 'Natale nei Musei' copiata da Facebook: un altro imbarazzo per il Campidoglio". Extraída el 16/X/2017 desde http:// roma.repubblica.it/cronaca/2017/01/02/news/roma_campagna_musei_plagio_facebook155291538/?refresh_ce

La Vanguardia (2013, octubre 15). "Banksy vende en la calle por $60 €$ obras que valen miles y nadie las compra". Extraída el 13/X/2017 desde http://www.lavanguardia. com/cultura/20131015/54391113583/banksy-vende-valiosas-obras-central-park-60dolares.html

Leal, A. y Quero, M. (2011). "Manual de marketing y comunicación cultural". Extraída el 12/X/2017 desde http://www.bizkaia.eus/home2/archivos/DPTO4/Temas/ producto44manual-de-marketing-y-comunicacion-cultural_web.pdf?idioma=EU

Martín,A.(2017), “El“Guernica”formalargascolasfrentealReinaSofía”.Extraídael16/X/2017 desde http://cultura.elpais.com/cultura/2017/04/12/actualidad/1492012061_260637.html

\section{Mateos Rusillo, S.}

_(2016, junio 20). "La exposición del Bosco, un tríptico de la museología actual”. Extraída el 16/X/2017 desde http://www.comunicacionpatrimonio.net/tag/publicidad/ (2013). "Museos y Content Marketing. Hacia un nuevo modelo de generación de contenidos culturales". ZER. Vol. 18, núm. 34, pp. 13-28. Extraída el 11/X/2017 desde $\mathrm{http}$ ://docplayer.es/3376377-Museos-y-content-marketing-hacia-un-nuevo-modelo-degeneracion-de-contenidos-culturales.html

(2011, octubre 3) "Museos y Relaciones Públicas: el poder de los nuevos prescriptores". Extraída el 13/X/2017 desde http://www.comunicacionpatrimonio.net/2011/10/museos-yrelaciones-publicas-el-poder-de-los-nuevos-prescriptores/

Mena García, E. (2016). "De cómo la publicidad se sirve de la historia del arte". Pensar la Publicidad, vol. 10, pp. 91-114.

Mendoza, I. (2013). “¿Qué es el marketing cultural?”. Extraída el 11/X/2017 desde http:// www.utel.edu.mx/blog/10-consejos-para/que-es-el-marketing-cultural/

Morte, P. (2004). “Las posibilidades publicitarias de Internet”. En López, R; Fernández, 
F. y Durán, A. (eds.) La publicidad local. III Congreso de Comunicación Local. Valencia: Universitat Jaume I.

Museo de Orsay (2006). “Orsay: un nouveau regard”. Extraída el 16/X/2017 desde http:// www.musee-orsay.fr/fr/collections/bienvenue/orsay-un-nouveau-regard.html

Navarro, C. (2010). Creatividad publicitaria eficaz. Madrid: ESIC.

Olamendi, G. (2000). Marcas y nombres. Casi todas las técnicas y trucos para crear marcas de éxito con nombres inolvidables. Bilbao: Olamendi.

Palma, L. y Aguado, F. (2011). “¿Debe el Estado financiar las artes y la cultura? Revisión de literatura". Economia e Sociedade. Vol. 20, núm. 1 (41), pp. 195-228. Extraída el 16/X/2017 desde http://www.scielo.br/pdf/ecos/v20n1/v20n1a08.pdf

UNESCO (2015). “Igualdad de género. Patrimonio y creatividad”. Extraída el 13/X/2017 desde http://www.unesco.org/new/fileadmin/MULTIMEDIA/FIELD/Mexico/informe.pdf

Unzueta, S. (2002). "El mercado del arte”. Boletín económico de ICE, núm. 2747. Extraída el 12/X/2017 desde http://www.revistasice.info/cachepdf/BICE_2747_35-43 DCD7F19FD425A2733746BDC8705E9768.pdf

Vicente, A. (2016, mayo 26). "El artista urbano JR 'borra' la pirámide del Louvre". Extraída el 13/X/2017 desde http://cultura.elpais.com/cultura/2016/05/26/ actualidad/1464269887_440663.html 